\title{
Improved Energy Management of Capacitive Energy Storage in Metro Railcar by Simulation
}

\author{
Istvan Szenasy \\ Department of Automation \\ Szechenyi University \\ 9026 Gyor (Hungary)
}

Phone/Fax number:+0036 96503462/+0036 96503461, e-mail: szenasy@sze.hu

\begin{abstract}
This paper focuses on the use of modeling and simulation of a renewable energy. The capacitive energy storages contribute to the rapid energy recovery associated with regenerative braking in electric vehicles. This power system allows the acceleration and deceleration of the vehicle with a lower loss of energy. Short-distance passenger traffic on electrified lines is a domain where brake energy recuperation might reduce the total energy consumption significantly. In this paper the results of simulation models by Matlab-Simulink for an urban-metro railcar and some methods for reducing the needed value of capacitance by an improved energy management are presented. The aim of the new management of the energy storage system for decreasing the needed value of capacitance and improving the system performance is presented.
\end{abstract}

Key words: electric vehicle, regenerative braking, energy storage, supercapacitor, Matlab simulation.

\section{Introduction}

Recent developments in energy storage devices, particularly supercapacitors and flywheels have made energy storage as viable technology to apply to railway systems. Energy storage devices can be used to improve the poor voltage regulation and the energy efficiency by storing regenerated energy from braking. This paper investigates the use of energy storage in mass transit systems, considering Budapest Metro Railway as a theoretical case study. For improving the better use of the built energy storage devices some ideas and conceptions were investigated through different way by a supposed energy management.
Overall system efficiency gains can be achieved by regenerating onto the overhead line. The effectiveness of regenerative braking is depends on the receptivity of the system. If no other trains are motoring within the section, the regenerated energy cannot be used, and the energy has to be dissipated through resistor banks. This problem can be avoided by using energy storage devices which can store regenerated energy on board trains or at the track side. On board stored energy provides an additional power source for acceleration, hence reducing the acceleration currents drawn from the overhead line and therefore reducing the magnitude of voltage sags.

\section{The modell of the railcar and its energy storage system}

Supercapacitors are new components that can be used for short-duration energy storage [1],[2],[3],[4],[5]. In comparison to standard batteries, the energy density of supercapacitor is lower by an average factor of 10 , but their energy density is compatible with a large range of power applications that need high instantaneous power during short periods of time. These characteristics are typically found in transportation systems.

The aim of this paper is to present how capacitive storage can be used for increasing the energy efficiency in a metro railway system and decreasing the needed capacitance for the energy storage. More train of railcars have DC drive via 4/4 operated converters. In this railcars a capacitive energy-storage device can be imaginable. In the Fig. 1 illustrates a railcar model. Main railcar characteristics are: the weight without load is $34 \mathrm{t}$, while the weight fully loaded is $44 \mathrm{t}$. The four DC motors' total power is $200 \mathrm{~kW}$, the nominal speed is $75 \mathrm{~km} / \mathrm{h}$, the maximum acceleration is more than $1 \mathrm{~m} / \mathrm{s}^{2}$, and the distances are approximately $800 \mathrm{~m}$ between stations. The 
basic initial conditions were as follows: the distance between stations is $800 \mathrm{~m}$, the mass one of the railcar is $40 \mathrm{t}$, the speed maximum is $75 \mathrm{~km} / \mathrm{h}$, and the grade is 0 \%o. In the Fig.1 does not show that the magnetic field of the motors is changeable. The weakening of field is begins over the speed of $36 \mathrm{~km} / \mathrm{h}$.

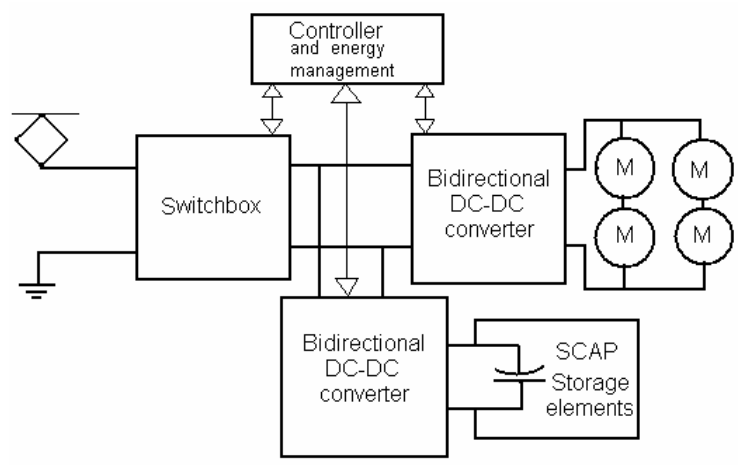

Fig. 1. Railcar model

conditions. In the previous papers [7], [8] was be analyzed some possibilities for decreasing the needed value of the minimum capacitance for storaging the energy from regenerative braking were analysed. The first attained object was the $840 \mathrm{~V}$ the initial voltage value of supercapacitor $C$ voltage, which we can be calculated from the value of the capacitance $\mathrm{C}$ and the "beforehand charged energy" $\mathrm{E}_{\mathrm{Co}}$ into $\mathrm{C}$ for attaining this voltage. In this paper the least voltage of $\mathrm{C}$ through the discharge is set for $400 \mathrm{~V}$, what we set by tuning the variation of the value capacitance $C$ by the beforehand charged energy $\mathrm{E}_{\mathrm{Co}}$ and the "constant charging power" $\mathrm{P}_{\mathrm{Ct}}$ through the execution of Matlab-Simulink program.

The aim of the investigation is to determine the least needed capacitance value of the supercapacitor (C) for different. This nature of this system was yet manifested at the beginning of the investigations through the executions. The Fig. 2 shows the direction of the simulation.

The adequate degree of the constant charging-power $\mathrm{P}_{\mathrm{ct}}$ is determined by the energy consumption of the motors, namely from the conditions of the transport and the parameters of the railcar. Accordingly the important aim of the investigation was to determine the adequate value of the constant charging-power $\mathrm{P}_{\mathrm{Ct}}$ and the least possible capacitance value for $\mathrm{C}$.

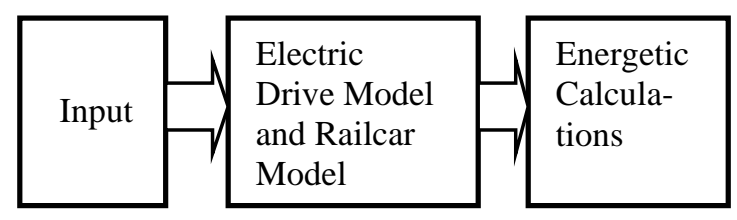

Fig. 2. Aim and direction of simulation and calculations

The executions of the program were through two distances of the stations. The energy consumption of the railcar and the diverse losses were calculated by the model too. The energy consumption of motors $E_{\text {mot }}$ are plotted also on the figures where these values have been take into consideration for the calculation of the rate of regenerated energy. Practically the energy consumption is divided by the running time given by the approximate value of the constant charging-power $\mathrm{P}_{\mathrm{Ct}}$ was needed for tuning.

In this paper in the investigations the value of $d$

$$
\mathrm{d}=\left(\mathrm{Uc}_{\min } / \mathrm{Uc}_{\max }\right) 100
$$

is about $48 \%$ if the $\mathrm{Uc}_{\min }$ is $400 \mathrm{~V}$.

The speed, the covered distance, the motor currents and powers are shown in Fig. 3. The mass is varied from 30 to $55 \mathrm{t}$, the grade is $0 \%$, the distance on between stations is $800 \mathrm{~m}$. The railcar is running the distances two times $800 \mathrm{~m}$ in $220 \mathrm{~s}$ in which there are two durations of stay. Effects of the mass differences for these curves are well visible.

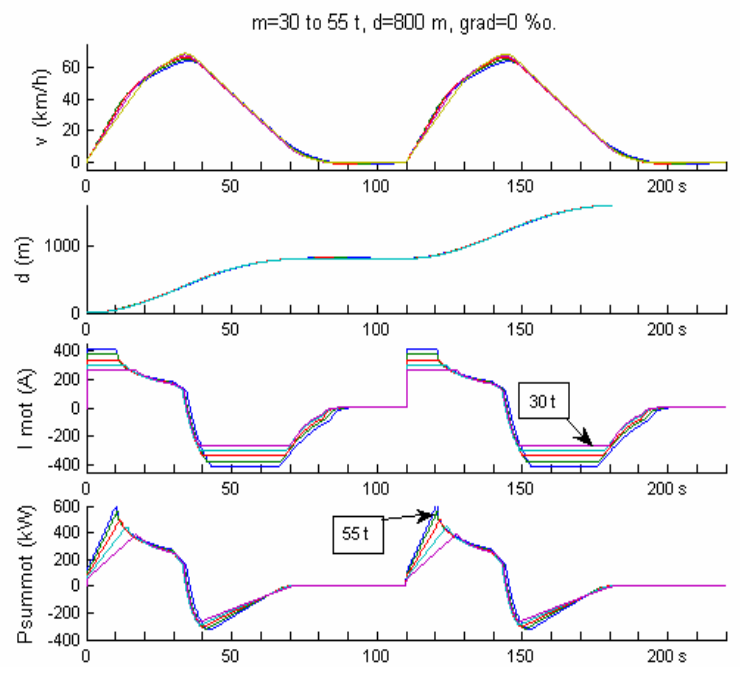

Fig. 3. The speed, the covered distance, the motor currents and powers on distance between stations, here $800 \mathrm{~m}$

The curves of "constant charging power" $\mathrm{P}_{\mathrm{Ct}}$, the needed capacitance $\mathrm{C}$ and the beforehand charged energy $\mathrm{E}_{\mathrm{Co}}$ here are functions of mass, speed, executed distance and grade.

The abbreviation "corrfact" means "a correct factor" for achieving a decreasing value of $\mathrm{C}$. There are some cases possible e.g. in shorter running time the applied charged energy $\mathrm{E}_{\mathrm{Ct}}$ by the method "constant charging power" $\mathrm{P}_{\mathrm{Ct}}$ is lower than it is needed, so the charged energy to $C$ is less. At this time the voltage of $\mathrm{C}$ decreases under $400 \mathrm{~V}$.

Instead of increasing the value of the $\mathrm{P}_{\mathrm{Ct}}$ there is a novel possibility to improve this problem. If the charging power is not only a constant value but is varied by some function of the total motor current or motor power under time of traction, than the charging of the $\mathrm{C}$ is more rapid and the needed value of the $\mathrm{C}$ will be less. Consequently the charging power has two components, a function of motor power by the "correction factor" and a much lower "constant charging power”, $\mathrm{P}_{\mathrm{Ct}}$. 
In this paper some kind of function was investigated for this improving method, in the first place directly proportional to the motor power. The applied "correction factor" means a proportion of the motoring power by which the railcar get down the current from overhead line for the motors, under controlling of energy management. By the method of "constant charging power" the energy is mainly flows from the $\mathrm{C}$ and a little part from overhead line. With this novel method this rate is almost inversely. Its effectiveness in decreasing of the $\mathrm{C}$ is higher because at "correct factor" 0.4 the used energy by motors flows from line in rate of $60 \%$ from the $\mathrm{C}$ and $40 \%$. This increasing in the current from the line decreases the needed value of $\mathrm{C}$. The results are shown in the Fig. 4.

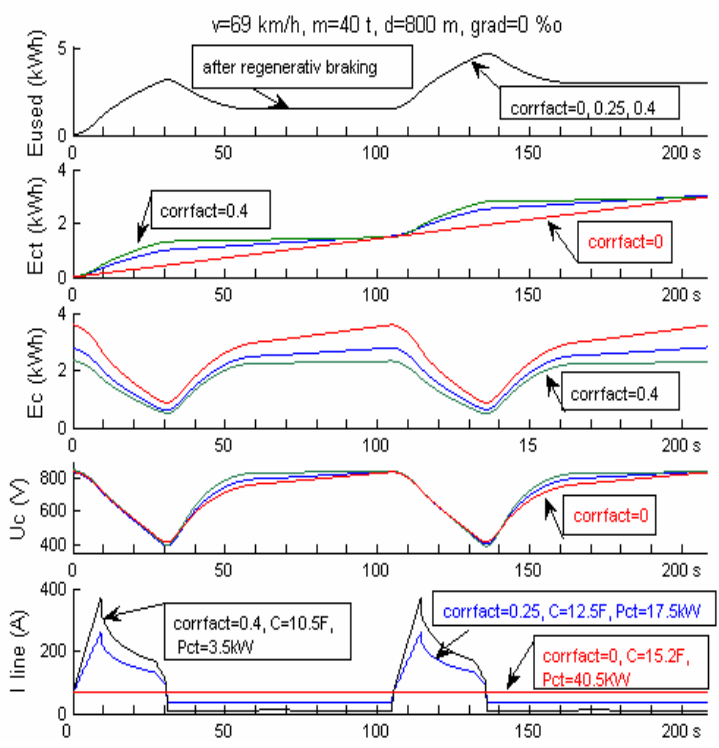

Figure 4 . The changed correction factor values and its effects at the same traction case

If this correction factor is zero than the improving process is out of operation. At value of this factor 0.4 there is an optimum among some considerations. By greater than 0.4 the correction factor may be 1.0 too, and in this case the changes of the current of overhead line are the same as in cases without $\mathrm{P}_{\mathrm{Ct}}$.

In the case if this factor is from 0.4 to 0.6 , the needed value of capacitance should be less, but at regenerative braking for storaging this energy the value of $\mathrm{C}$ is insufficient, as had be shown after some executions. The sensibly greatest value for this correction factor was selected to 0.4 .

In the Fig. 4 as the same course of metro car is seen but the set of energy management is varied by value of the correction factor from 0 to 0.25 and to 0.4 . As can be seen the curve $E_{\text {used }}$ the energy consumption of the car is not varied by varied this correction factor. The curves of charged energy $\mathrm{E}_{\mathrm{Ct}}$ by the constant charging power $\mathrm{P}_{\mathrm{Ct}}$ are varied according to the value of correction factor. In lowest figure can be seen well the effects of this setting. The overhead line currant curves are changed according to value of $\mathrm{P}_{\mathrm{Ct}}$ and the correction factor. If this value is zero the $\mathrm{P}_{\mathrm{Ct}}$ will be the greatest and under time is constant. If the value of correction factor is not zero the curves $\mathrm{P}_{\mathrm{Ct}}$ are lower and under time of traction there is a charging according to motor power and correction factor.

The decreasing ratio of the needed capacitance $\mathrm{C}$ is about from 25 to $35 \%$ comparing to the value of the correction factor is zero that was in the cases in the previous papers by $\mathrm{P}_{\mathrm{Ct}}=$ const. The charged energy $\mathrm{E}_{\mathrm{Ch}}$ to the $\mathrm{C}$ by charger power $\mathrm{P}_{\mathrm{Ch}}$ is

Ech $=\int_{0}^{t} P c h d t=\int_{0}^{t} P c t d t+\operatorname{corrfact} * \int_{0}^{t} P \operatorname{Pmot} d t$

This energy management as a control task is executable with the controller by measuring the motor currant and voltage, the speed, the voltage of the line and calculating the motor power.

The system can change the voltage levels by setting the suitable charging or discharging current of the capacitance.

In the Fig. 3 upper detail-figure under the notice "after regenerative braking" there is the name of a section in which the sum of energy total-consumption is the lowest. The calculation of energy saving are executed by this values.

\section{Analyses of courses}

In Fig. 5 the curves are shown here for two distances between stations. In these executions the values of mass was varied and the motor currants are proportion to mass. The correction factor was 0.4 so the value of $\mathrm{C}$ and Pct are lower. In the lowest figure the current of the overhead line is presented.
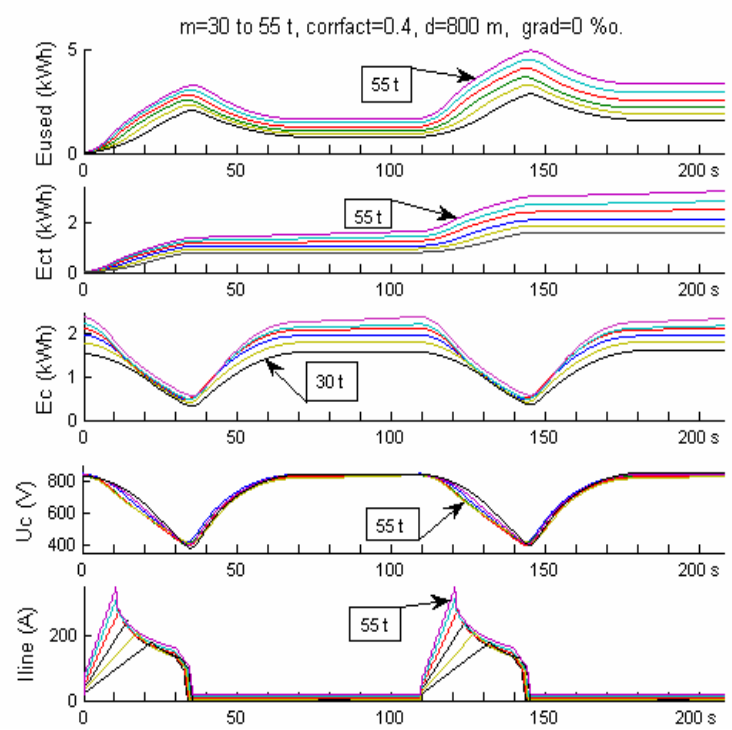

Figure 5. The values of mass are varied and the motor currents are proportion to mass. The corrfact $=0.4$, so the current of the overhead line is not constant.

This is not a constant as compared to the case when corrfact $=0$. In these curves there are two outstanding 
sections from the 0.4 times of traction power, to the constant lower values from $\mathrm{P}_{\mathrm{Ct}}$. In the Fig. 6 the speed is varied. Because of this at lower speeds the later points of the curves are sliding on the time axis. For keeping the $d$ voltage-ratio of $U_{C}$ and at the same time increasing the mass, speed and grad, than the value of $\mathrm{C}, \mathrm{E}_{\mathrm{Co}}$ and $\mathrm{P}_{\mathrm{Ct}}$ need to be increased, too.

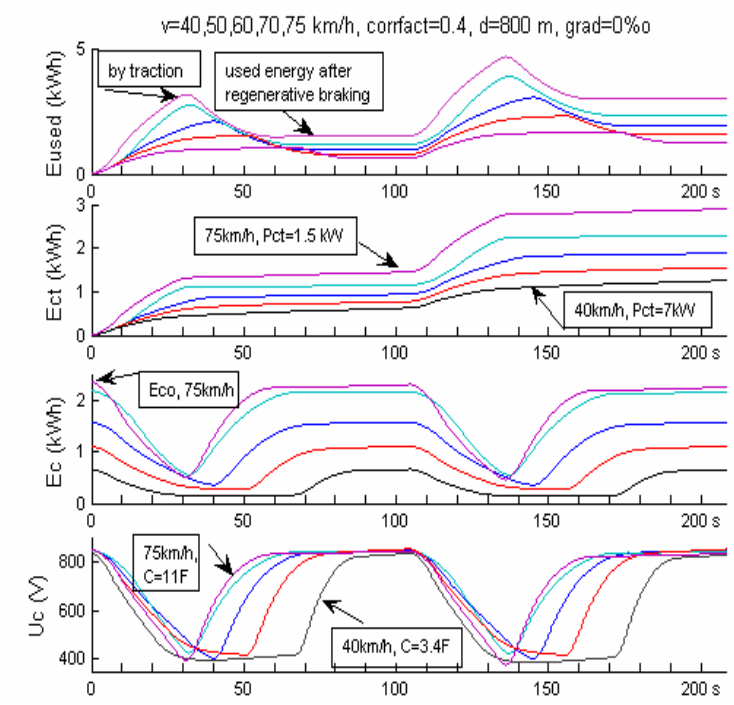

Figure 6 . The speed is varied. The lowest values of needed $C$ and $\mathrm{P}_{\mathrm{Ct}}$ at corrfact $=0.4$ are shown and are function of speed.

In Fig. 7 the correction factor was 0.4 and the grade was varied from -20 to $20 \%$ o. The motor currents were not proportion to the grade. Its maximum value is $300 \mathrm{~A}$. The current of the overhead line depends on the grade. The current flows from the line through to DC-DC converters to the motors and after motoring part to the $\mathrm{C}$.

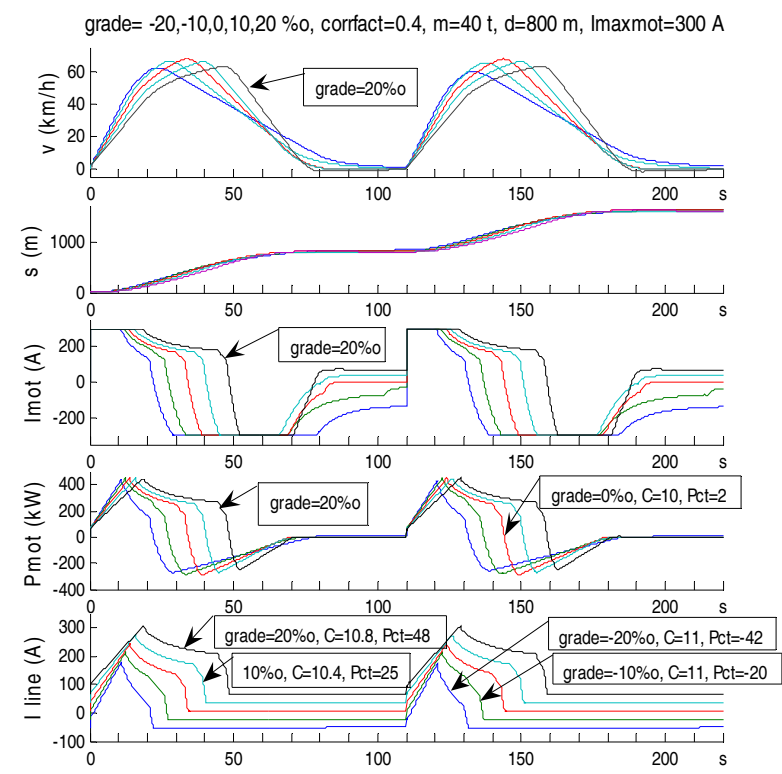

Figure 7. The grade is varied. The lowest values of needed $\mathrm{C}$ and $\mathrm{P}_{\mathrm{Ct}}$ at corrfact $=0.4$ are shown

The acceleration takes a longer time on $10 \%$ and $20 \%$ o grades regarding the motor current maximum is $300 \mathrm{~A}$.
Down below the changes of currents of line under and after motoring are illustrated.

The possible lowest values of needed $\mathrm{C}$ and $\mathrm{P}_{\mathrm{Ct}}$ at corrfact $=0.4$ are signed in the figure. If the grade $=0 \%$, the value of $\mathrm{C}$ is $10(\mathrm{~F})$, but if the grad are $20 \%$ and -20 $\%$, the needed minimum value of $\mathrm{C}$ are 10.8 and $11(\mathrm{~F})$. The alteration of the needed value of $\mathrm{C}$ between the 20 $\%$ o and $-20 \%$ is very small. At the same time the energy flow provided by DC-DC converters are very different, the $\mathrm{P}_{\mathrm{Ct}}$ is $48 \mathrm{~kW}$ at $20 \% \mathrm{o}$ and $-42 \mathrm{~kW}$ at -20 $\%$. In the latter case it is necessary that the overhead line must be able to receive the energy from railcar. If not, this energy will be dissipated on the braking resistor. For storing this energy in $\mathrm{C}$, the value of capacitance needs to be increased significantly which should be economical if this occurs frequently e.g. in more section on the traffic line.

In the curves shown Fig. 8 are correspond almost the same case as Fig. 7. The grade was varied from -20 to 20 $\%$ o but the change of motor currents was proportions to the grade. At grade $20 \%$ o the current is increased to 360 A from $300 \mathrm{~A}$. It was needed to increase the minimum value of capacitance $\mathrm{C}$ too from $10(\mathrm{~F})$ to $11.6(\mathrm{~F})$ at the grade $20 \%$. For storing the braking energy at this section we have increased the capacitance until 15 (F) and this it was sufficient to storage at the grade $-20 \%$. At this case the negative signed "constant charging power” $\mathrm{P}_{\mathrm{Ct}}$ was zero.

Fig. 9 presents the curve of the saved energy v. grade. The values of the saved energy are available if the traffic occurs on a constant grade. In real urban railway traffic conditions this curve is not available regarding the grades generally are not long.

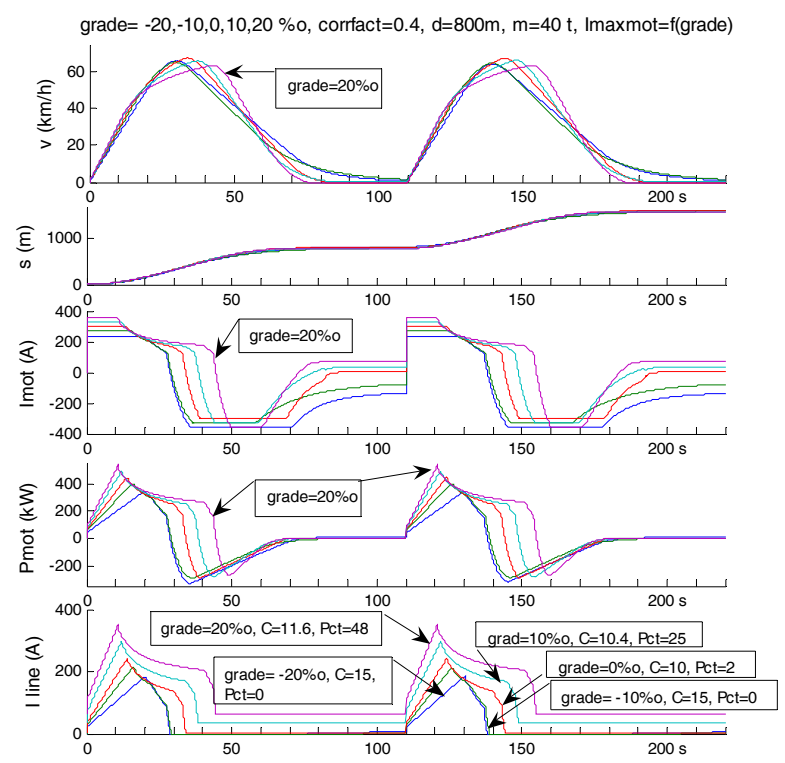

Figure 8 . The grade is varied, the currents maximum are proportion to grades. The corrfact $=0.4$, so the current of the overhead line is not constant. 
This model gives possibilities to investigate any combination of uphill and downhill.

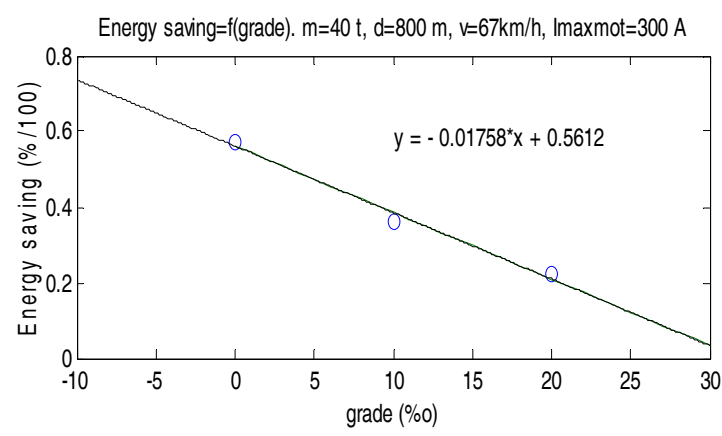

Figure 9. The saved energy v. the grade by conditions written in figure

Fig. 10 presents the needed capacitance of the energy storage $\mathrm{v}$. the speed in case when the maximum of motor current is $300 \mathrm{~A}$, the distance between station $800 \mathrm{~m}$, the mass of a car $40 \mathrm{t}$, and the grade is $0 \%$. In this investigation the correct factor was 0.4 .

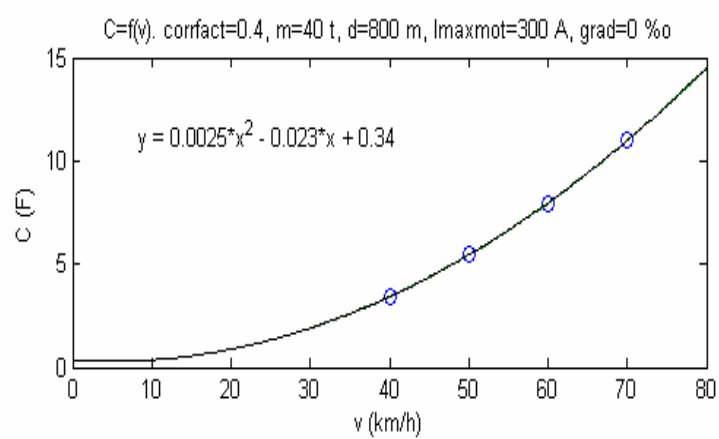

Figure 10. The needed capacitance of the energy storage v. speed under conditions written in figure

The functions for $\mathrm{C}_{\text {needed }}, \mathrm{P}_{\mathrm{Ct}}, \mathrm{E}_{\mathrm{C} 0}, \mathrm{E}_{\text {used }}, \mathrm{E}_{\text {saved }} \mathrm{V}$. mass, speed, distance of between station for theses 5 to 6 values are calculated and fitted good with least square method by Matlab.

The Fig. 11 presents the energy saving as two-variable function $\mathrm{v}$. the speed $(\mathrm{km} / \mathrm{h})$ and the mass $(\mathrm{m})$. This function here is a three-degree for the speed and twodegree for the mass.

$$
\mathrm{E}_{\text {saving }}=\mathrm{f}(\text { speed, mass })
$$

and as is calculated as

$$
\begin{array}{r}
E_{\text {saving }}=\mathrm{Z}=\left(9.167 \mathrm{e}-007 * \mathrm{X}^{3}-0.0003 * \mathrm{X}^{2}+0.02986 * \mathrm{X}\right. \\
\left.-0.2332-3.707 \mathrm{e}-005^{*} \mathrm{Y}^{2}-0.001764 * \mathrm{Y}\right)
\end{array}
$$

Energy saving $=f(v, m) . s=800 \mathrm{~m}$, grad $=0 \% 0$

Esaving $=Z=\left(9.167 \mathrm{e}-007^{*} X^{3}-0.0003^{*} X^{2}+0.02986^{*} X-0.3635-3.707 \mathrm{e}-005^{*} \gamma^{2}-0.001764^{*} \gamma+0.1303\right)$

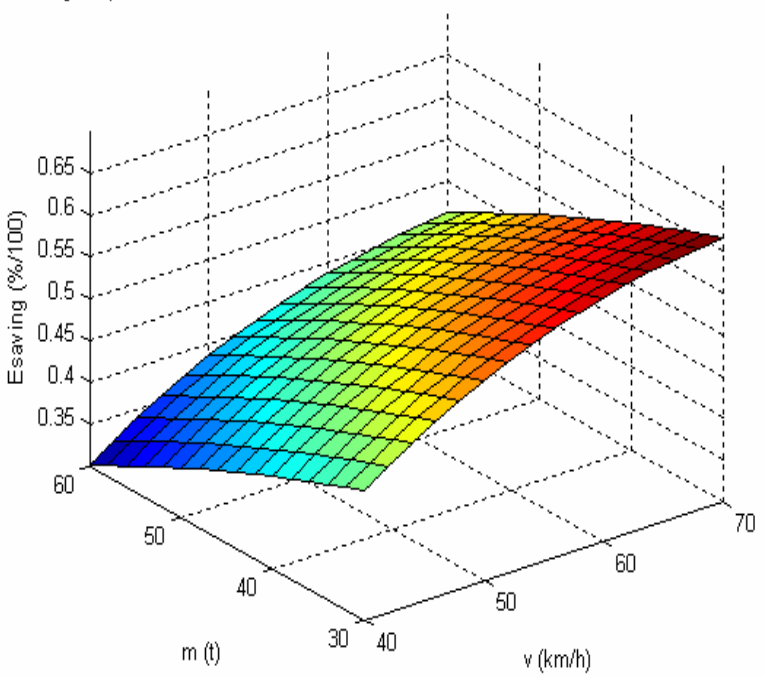

Figure 11. The simulated energy saving as two-variable function v. the speed $(\mathrm{km} / \mathrm{h})$ and the mass $(\mathrm{t})$

These efficiency values of energy saving here are rather high, but the losses of the supercapacitor is 1 to $2 \%$, and the one's of the DC-DC converter being upper $400 \mathrm{~kW}$ is 3 to $4 \%$. Only perhaps the application of fly-wheel batteries on the board can give such low losses.

Fig. 12 shows the energy saving. v. the speed $(\mathrm{km} / \mathrm{h})$ and the distance between stations ( $\mathrm{m}$ ).

$$
E_{\text {saving }}=\mathrm{f} \text { (speed, distance) }
$$

$$
\mathrm{E}_{\text {saving }}=\mathrm{Z}=\left(9.167 \mathrm{e}-007 * \mathrm{X}^{3}-0.0003 * \mathrm{X}^{2}+0.02986 * \mathrm{X}\right.
$$$$
\left.-1.399 \mathrm{e}-007 * \mathrm{Y}^{2}+0.0002943 * \mathrm{Y}-0.5209\right)
$$

$$
\begin{gathered}
\text { Energy saving }=f((, d) . m=40 t, \text { grad }=0 \% 0 . \\
\text { Esaving }=Z=\left(9.167 e-007^{*} X^{3}-0.0003^{*} X^{2}+0.02986^{*} X-0.3635-1.399 e-007^{*} \gamma^{2}+0.0002943^{*} \gamma-0.1574\right)
\end{gathered}
$$

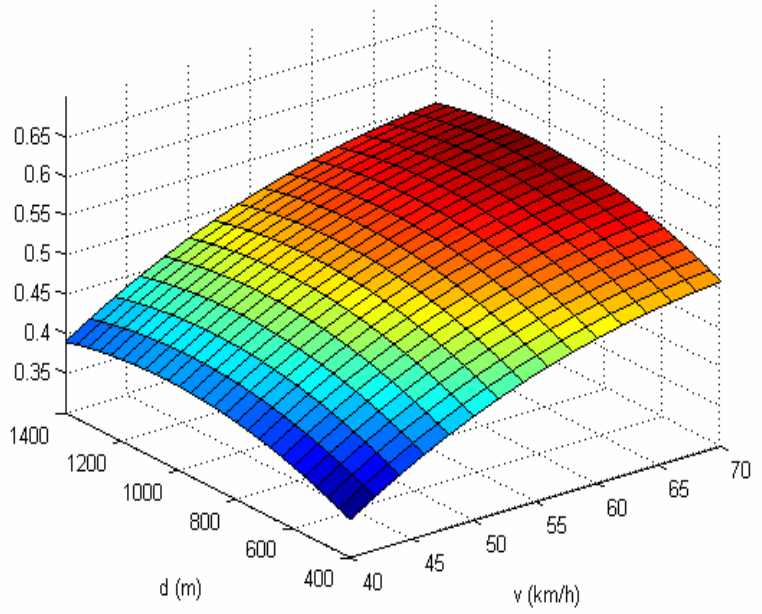

Figure 12 . The energy saving $\mathrm{v}$. the speed $(\mathrm{km} / \mathrm{h})$ and the distance of between stations (m).

Fig.13 illustrates the differences between the value of $\mathrm{C}_{\text {min }}$ in cases corrfact $=0$ and corrfact $=0.4 \mathrm{v}$. the speed $(\mathrm{km} / \mathrm{h})$ and mass $(\mathrm{t})$

$$
\mathrm{C}_{\text {corrfact0 }}-\mathrm{C}_{\text {corrfact } 0.4}=\mathrm{f} \text { (speed,mass) }
$$




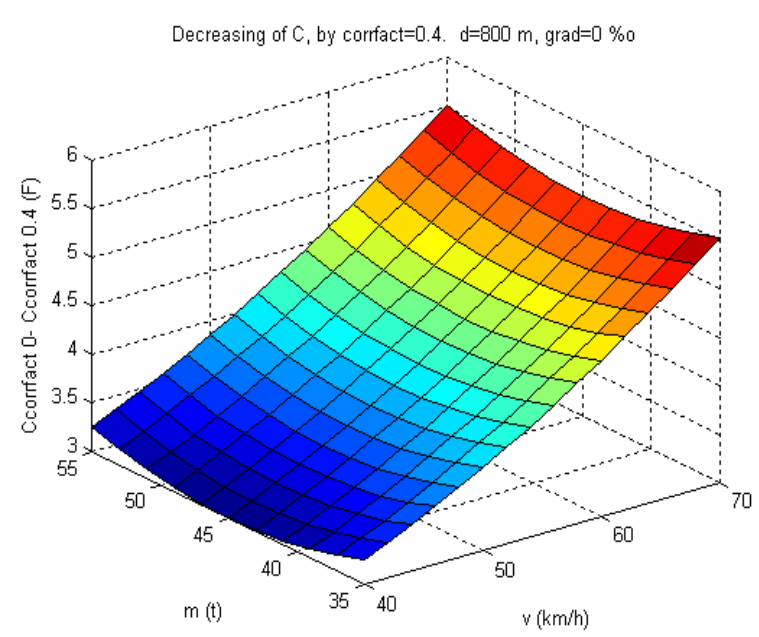

Figure 13. The decreases of the possible needed minimum values of the capacitance $\mathrm{C}_{\text {needed }}$ between corrfact $=0$ and corrfact $=0.4$.

The Fig. 14 represents the realization of the new energycontrol system as a part of a new energy management. The reference signal of the control circle is $\mathrm{X}_{\mathrm{rPcharge}}$ and the controled value is $\mathrm{Xs}_{\text {Pcharge }}$ in output side of charger converter.

The transfer function of the converter is $\mathrm{Y}_{\mathrm{ch}}$.

For compose reference signal this solution use two components:

- the output-side power signal from DC-DC converter feeds the motors. This signal is realised from the values of current and voltage, then by correct factor.

- $\quad$ set the values of $\mathrm{P}_{\mathrm{Ct}}$, and $\mathrm{E}_{\mathrm{C} 0}$, on base some previous investigations or experimented curses.

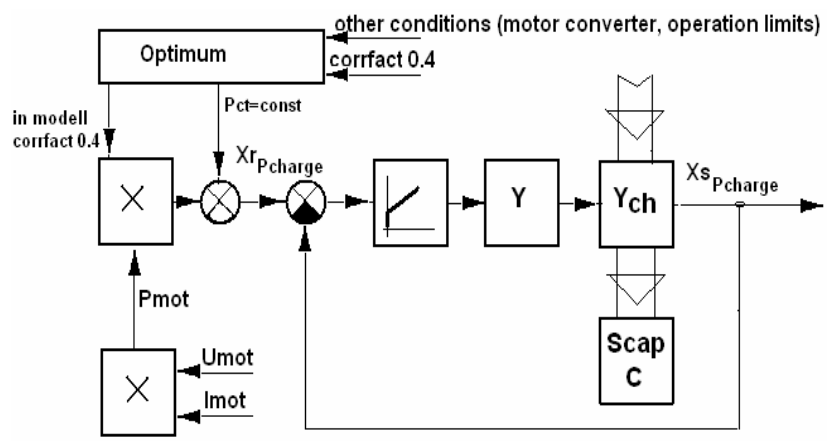

Figure 14. The links of the new energy-control system

In operating this control realizes a charger power regarding to reference signal and achieving by the charger converter. This power value is independent from voltage of capacitor or one of motors. This system cares to the actually needed charger power to decreasing the consumed energy by motors from energy storage.

\section{Conclusion}

We presented the reason and the advantages of applied "beforehand charged energy" $\mathrm{E}_{\mathrm{Co}}$ and "constant charging power" $\mathrm{P}_{\mathrm{Ct}}$ in simulation.

The "correction factor" means a proportion of the motoring power by which the railcar gets down the current from overhead line for the motors, under controlling of energy management.

The available decreasing ratio of the needed capacitance $\mathrm{C}$ with this improved energy control method is about from $25 \%$ to $35 \%$, significant value.

The available energy saving is over $40 \%$.

This novel process and its results are practically independent of the type of the traction motor.

In next periodes of this research will be investigated the Li-ion battery as energy storing device for the same task and its effectivness under operation of this energy control system.

\section{REFERENCES}

[1] P. Barrade: Energy storage and application with supercapacitors. leiwww.epfl.ch/publications/barrade_anae_03.pdf

[2] L. Guzzella, A.Scuaretta: Vehicule propulsion systems.ISBN 978-3-540-74691-1. Springer Verlag Berlin Heidelberg 2007.

[3] P.Barrade, a. Rufer: High power fast energy exchange between storage system: supercapacitors as energy buffer in transportation systems.

leiwww.epfl.ch/publications/destraz_barrade_rufer_ pesc_04.pd

[4] J.W. Dixon, M. Ortúzar, J. Moreno: Monitoring system for testing the performance of an electric vehicle using ultracapacitors.

www2.ing.puc.cl/power/publications/electronics.htm - 38k

[5] A. Rufer, P. Barrade: A supercapacitor based energy storage system for elevators with soft commutated interface.

ieeexplore.ieee.org/iel5/7586/20673/00955719.pdf -

[6] M. Chimera, A. Renfrew, M. Barnes: Energy storage devices in railway system. www.iee.org/oncomms/ pn/railway/06innovation_chymera.pdf

[7] I. Szenasy: Improvement the energy storage with ultracapacitor in metro railcar by modeling and simulation Vehicle Power and Propulsion Conference, 2008. VPPC '08. IEEE 3-5 Sept. 2008 ISBN: 978-1-4244-1848-0

[8] I. Szenasy: Modeling and simulation for the energy storage by ultracapacitor in urban rail car. ECT 2008 Conf. Kaunas, Lithuania.

[9] I. Szenasy: Dynamic energy storages applications for metro railcars with computed simulation. Dissertation for Budapest Technical University, 1994 (in Hungarian) 